\title{
The Summary of the Research on the Compound Braking Strategy of Four Wheel Hub Motor Drive Electric Vehicle
}

\author{
Peiteng Zhao, Huanhuan Zhang, Bo Peng \\ College of Automotive Engineering, Shanghai University of Engineering and Science, Shanghai, China \\ Email: tengpeizhao@sina.com
}

Received 23 June 2016; accepted 17 July 2016; published 20 July 2016

Copyright @ 2016 by authors and Scientific Research Publishing Inc.

This work is licensed under the Creative Commons Attribution International License (CC BY).

http://creativecommons.org/licenses/by/4.0/

c) (i) Open Access

\begin{abstract}
This paper describes in detail three kinds of typical compound braking strategy of wheel motor drive electric vehicle and summarizes the current commonly used strategies based on the three typical strategies developed. In the end, a new compound braking strategy is proposed; that is, we take braking mode classify, ECE regulations and SOC value of the battery as an important reference of braking force that joins the motor braking force, as well as we join the different identification models; according to the different braking modes, the purpose is that we can apply the different braking program.
\end{abstract}

\section{Keywords}

Wheel Hub Motor, Compound Braking, Strategy Research, Electric Vehicle

\section{Introduction}

Extending the driving distance is an important factor for the development of electric vehicles. In order to solve this problem that electric vehicle driving range is short, in addition to making a breakthrough in battery technology, how to save and use the vehicle energy will be an important topic and based on this research topic, renewable braking technology develops. Regenerative braking, also known as regenerative braking, during electric vehicle braking, vehicle kinetic or potential energy through the transmission system transmitted to the generator, then converted into electrical energy and charged the battery, so it can achieve the braking energy regeneration utilization [1]. At the same time, the dynamo braking torque produced by motor becomes the brake force through reverse motor. This will not only make regenerative braking energy recovery, also reduce the brake temperature, and improve the braking efficiency and safety performance. Combined braking strategy is an 
alternative that in the premise of ensuring safety electric vehicle can recover braking energy as much as possible. With the in-depth study of the technology of electric vehicle, the compound braking strategy is also applied to the four wheel hub motor drive electric vehicle, which is a new type of electric vehicle and has achieved a lot of results. The compound braking strategy methods usually about four wheel hub motor vehicles have the following: The first method is the control scheme of ideal brake force distribution, the second method is optimal feedback energy recovery control strategy, and the last method is that front and rear wheel braking force are distributed according to the fixed proportion.

\section{The Control Scheme of Ideal Brake Force Distribution}

According to the ideal braking force distribution control strategy, the proportion of the motor braking force is relatively large,and the ideal braking force distribution curve are similar with I curve of the traditional vehicle, priority to consider the safety of vehicle braking, and are similar with the traditional vehicle brake feel, in the braking force distribution, according to the ideal braking force distribution curve to distribute the braking force between front and rear axle wheels, the running distance of the vehicle in the whole braking process can be achieved by controlling the braking time and the front and rear wheels of the vehicle to achieve the whole braking process for enabling the driver get the best braking sense. The best braking sense of the series way ensure that the braking distance of meet the needs of the driver. However, the control scheme needs to make the front and rear wheels to be distributed in strict accordance with the ideal braking force distribution curve, which requires complex control strategy and execution mechanism [2] [3].

\section{Optimal Feedback Energy Recovery Control Strategy}

The core idea of this control strategy is that under the ensuring the safety of braking, as far as possible to allow the motor to participate in the braking. When the vehicle braking strength is lower than the motor can provide the maximum braking intensity, the motor provides braking moment,when the vehicle's braking intensity exceeds the motor that can provide the maximum braking strength, motor will full load in the brake, and traditional hydraulic braking system torque is that the difference between the total braking torque and motor braking torque, the purpose is to ensure the maximum braking energy recovery rate. In addition, its front and rear braking force is distributed according to the ideal braking force distribution curve. The recovery rate of this control strategy is relatively high, but it is difficult to achieve because of the complexity of the control strategy and the implementation mechanism.

\section{Front and Rear Wheel Braking Force Are Distributed According to the Fixed Proportion}

According to the fixed proportion distribution control scheme, the braking force distribution of front and rear wheels is consistent with the original model, that is, the front and the rear wheel braking force distribution curve is still $\beta$ line [4]. This scheme will not change the driver's braking habits, and can recover a part of the braking energy. But for the four wheel motor drive electric vehicle, the braking scheme will let the front and rear wheel hub motor regeneration braking force different, has made a difference in the amount of four in wheel motor power, and have an effect on balance charge, so it need additional controller to control and increase the cost and difficulty in research and development.

\section{Innovation Method}

We take braking mode classify and take ECE regulations, SOC value of the battery as an important reference of braking force that join the motor braking force, as well as join the different identification models, according to the different braking modes, use the different braking program. Due to the safety of the automobile braking energy recovery process, the precision of the judgment of the braking mode,and the recovery energy is much, so the control scheme is widely used.

The biggest characteristic of this kind of control scheme is divided intothree state: emergency brake, slight brake and normal brake. Then the corresponding different braking strategy is put forward based on the three kinds of states.

The following conditions are the prerequisite for the implementation of the programme: 
(1) ECE regulation: In order to ensure the stability of the vehicle's direction and the sufficient braking efficiency, the R13 ECE braking regulations are formulated by the European Economic Commission of the United Nations, the R13 ECE braking regulationsmade clear requirements on the front and rear wheel brake system of double axles vehicle. The industry standard (24007-1989 ZBT) of our country also put forward the similar request. Regulations: for $\psi=0.2-0.8$ between various types of vehicles, brake strength $\mathrm{z} \geq 0.1+0.85$ $(\psi-0.2)$ vehicles in various loading conditions, front axle by attachment coefficient curve in the rear axle utilization adhesion coefficient curve. For the car, brake strength lies in between 0.3 and 0.4 . If rear axle using adhesion coefficient curve is less than linear $\mathrm{z}+0.05$, allowing the rear axle utilization adhesion coefficient curve above in the front and rear the attachment coefficient curve(as shown in Figure 1).

(2) Battery SOC value: the performance index of the battery is very big to the braking energy recovery [5]-[7]. The remaining charge of the battery is the SOC value of the state of charge of the battery. At present, the definition of the remaining power is that define the remaining powerfrom the point of view of power. This means that under certain discharge rate conditions, the ratio of the residual capacity of the battery and the rated capacity under the same conditions.

$$
\mathrm{SOC}=\frac{c_{o}}{c_{e}}
$$

$c_{o}$ : Remaining capacity of battery. $c_{e}$ : Rated capacity of battery. Generally, if battery charge is full, then $\mathrm{SOC}=1$. If battery discharge to the situation cannot continue to discharge, then $\mathrm{SOC}=0$. It should be noted that, in order to avoid excessive discharge of the battery, usually in the case of SOC $>0.9$, we should control the motor not to charge the battery [8].

(3) Regenerative braking force of wheel hub motor

In the process of energy recovery of electric vehicle driven by four wheel hub motor,the maximum braking force of the wheel motor should be the minimum value between the peak torque of the motor and the maximum charging power of the battery.

Through speed and threshold value or driver intention recognition models, (such as Markov model, fuzzy control theory, neural network, etc.) can judge brake conditions of car, which is in need of emergency braking, the slight brake or normal braking. According to these three kinds of braking conditions, various braking strategies are put forward.

Firstly, finding out method for dividing a range of minor braking, normal braking and emergency braking.

Secendly, finding out method for braking forceof front and rear allocation. Chao He Tianput forward a braking scheme in his article: When the brake signal generated, firstly,according to the brake pedal signal and current speed, brake control unit (BCU) calculate the total braking force and renewable braking force provided

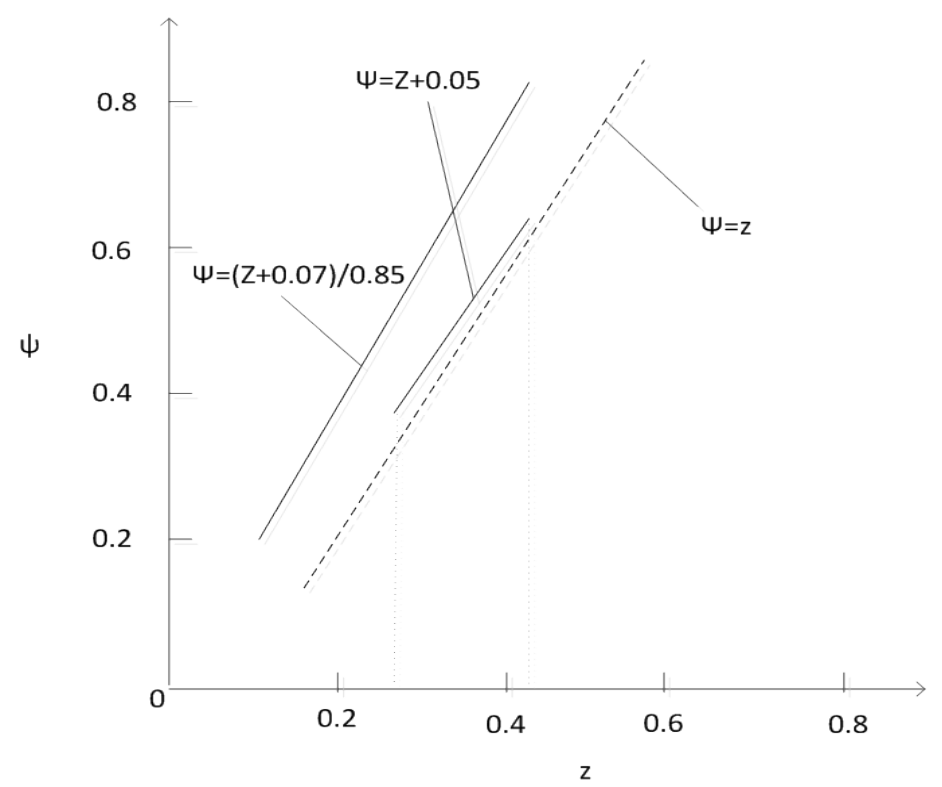

Figure 1. Raking force distribution of ECE regulations. $\mathrm{z}$ stand for brake strength, $\psi$ stand for using adhesion coefficient. 
by the hub motor, and judging whether to join the mechanical brake. The signals are respectively transmitted to the wheel motor braking system and the mechanical braking system. The braking system generates the corresponding braking force to brake the vehicle. At the same time, through a number of sensors to detect vehicle speed, SOC value of the battery and the maximum charage power of the battery, etc., and let the signal feedback to the brake control unit, the power of each conduct distribution and real-time adjustment [7]. Compound braking control strategy is shown in Figure 2.

Such as the scheme proposed by Dawei Li in his article: According to the braking strength size, we can divided into three kinds of brake, when brake strength is small, we adopt the electric braking, when braking intensity is large, we adopt the mechanical braking force, when braking strength somewhere in between the twos, electrical power and mechanical braking force are distributed according to a fixed proportion. The braking force distribution curve is determined according to ECE braking regulations, through the calculation,we canachieve the front and rear axle braking force distribution curve and electric braking and mechanical braking force distribution curve, and then obtain the share of the braking force in the whole braking process [8]-[11].

Based on the above research, this paper also puts forward a kind of strategy method (The flow chart of the strategy is shown in Figure 3).

According to the model of braking intention recognition (markoff model, fuzzy recognition model, etc.), when the brake signal is generated, it will be judged that this is an emergency brake, a normal brake, or a slight brake. Brake control unit determines whether need to add mechanical brakingforce. According to the situation and speed calculated the total braking force and the hub motor can provide the regenerative braking force and the signals were transmitted to the hub motor braking system and mechanical brake system, the braking system generates the corresponding braking force to brake the vehicle. At the same time, through a number of sensors to check the speed, the battery SOC value and the maximum battery power, etc., and put the signal feedback to the brake control unit, and distribute the power and real-time adjust the system [12].

When the car is in an emergency brake mode, the motor brake and mechanical brake will be involved in, for the front and rear force of braking system, the braking force will be distributed according to the actual braking force distribution curve. And motor braking force will be added by changing the value of the power of the wheel electric mechanism in a certain range. According to the distribution of the most close to the ideal braking force distribution curve, dynamic distribution curve of the front and rear wheels will distributed, as shown in Figure 4. The purpose is to make the power system more safe and effective.

When it is the normal braking mode and the braking force of the wheel hub motor cannot meet the total demand braking force, the residual braking force is added by the mechanical braking force, and according to the dynamic distribution coefficient of the front and rear wheels of the original model, the motor braking and mechanical braking force of the front and rear wheels are distributed. With the reduction of the demand for power, the motor braking force will gradually participate in, the mechanical braking force will slowly withdraw from the composite brake [13]-[15].

When the automobile is a slight brake mode, the vehicle is provided with regenerative braking by the wheel hub motor, and the battery is charged by the power of wheel hub motor produced.

In the process of braking, if the power of battery is higher, in order to prevent over charging, the energy of the wheel motor brake produced is not charged to the battery, which is consumed by the energy dissipation device.

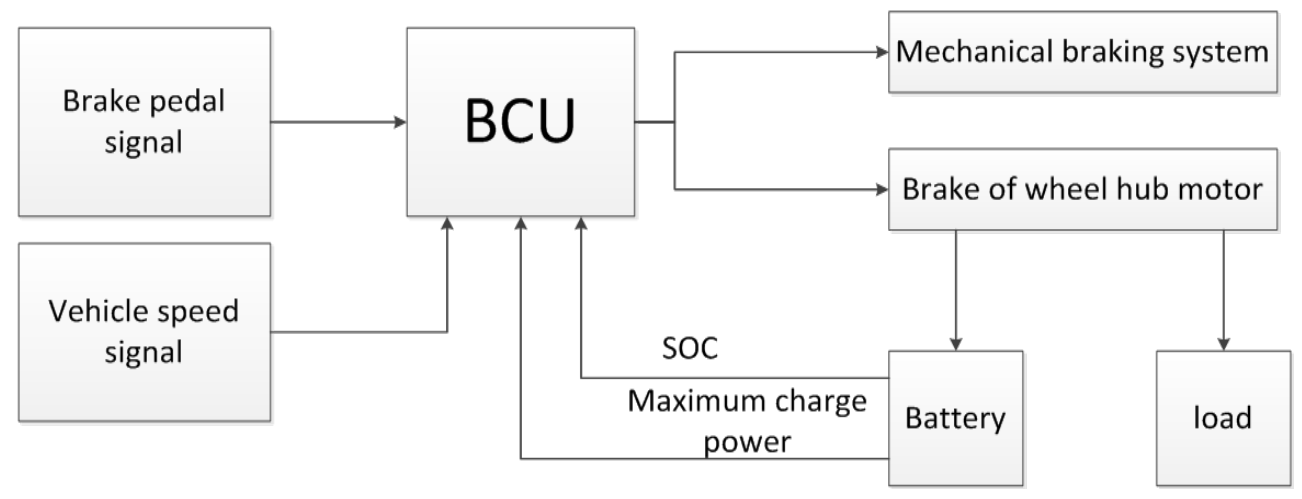

Figure 2. Wheel motor regenerative braking control logic diagram. 


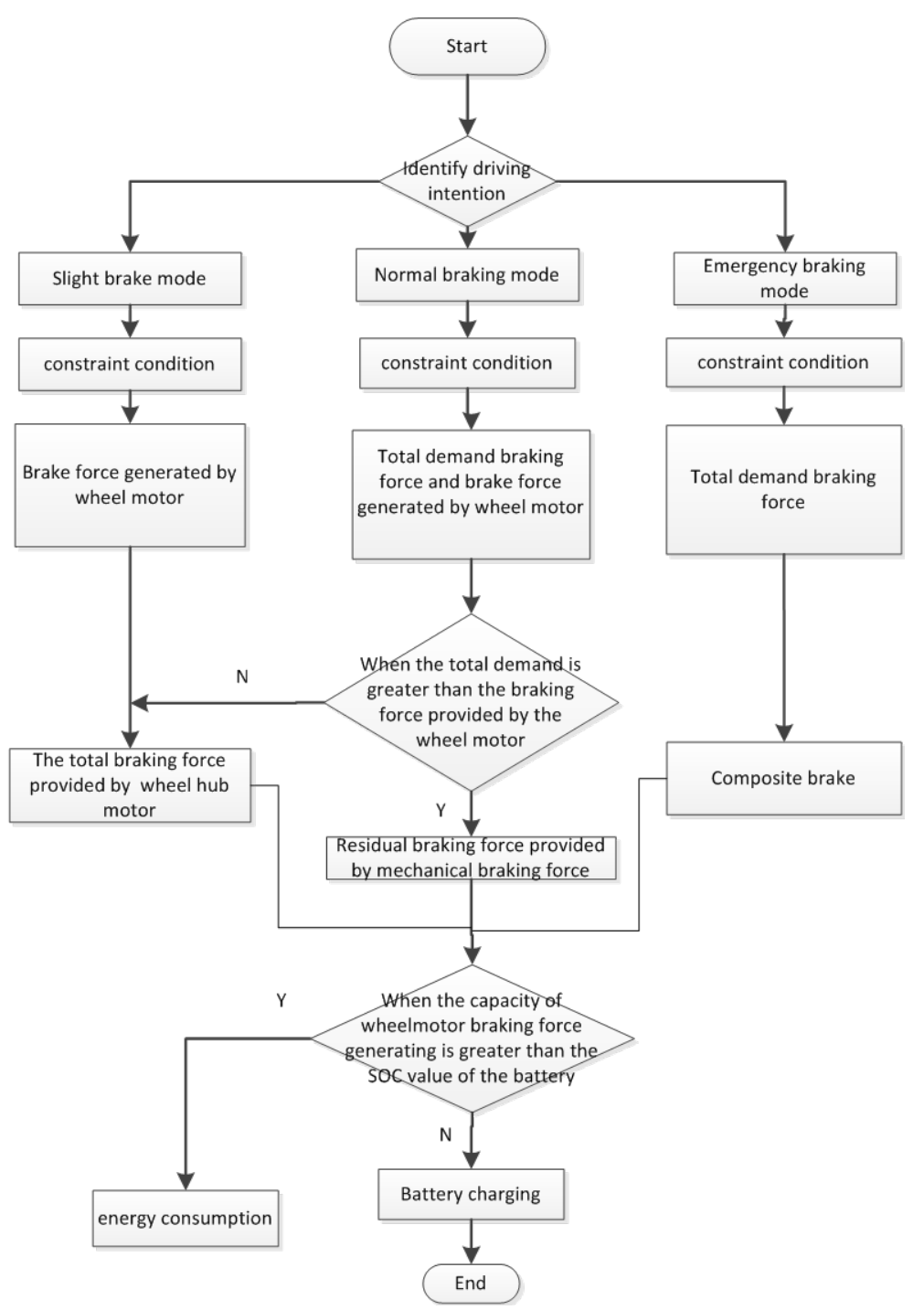

Figure 3. The flow chart of the compound braking force distribution strategy under different braking modes.

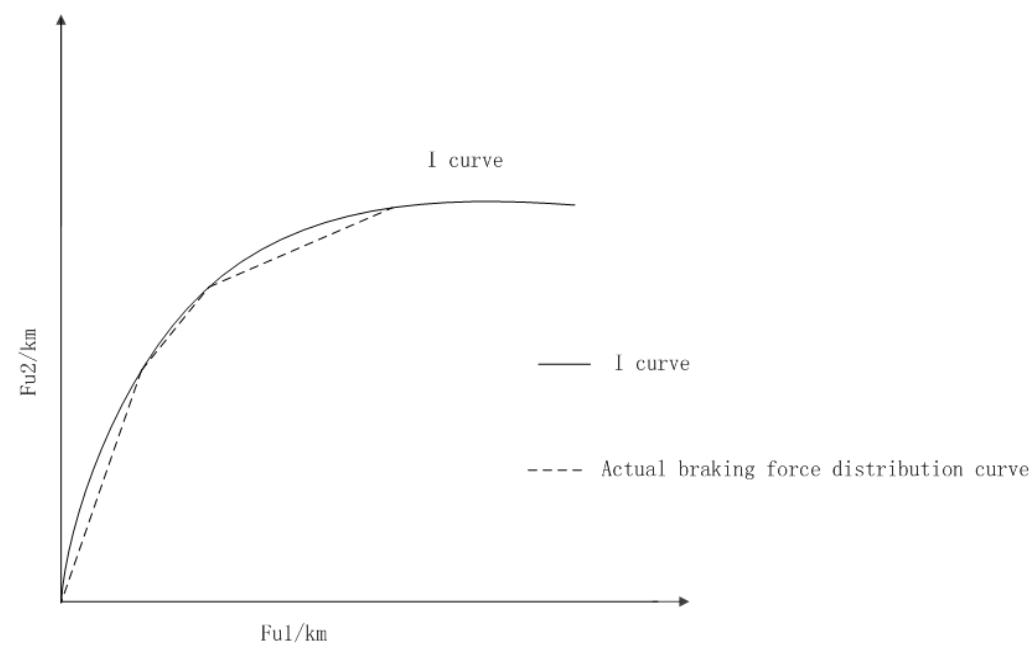

Figure 4. Under the emergency braking mode, the braking force distribution curve. 


\section{Conclusion}

Through the above summary we can learn that, in the future, the development direction of the compound braking strategy is the fourth kinds of strategies, which can improve the safety of automobile braking, the maximum energy recovery and the feasibility of the program execution.

\section{Acknowledgements}

I want to take this chance to thanks to my tutor. In the process of composing this paper, she gives me many academic and constructive advices, and helps me to correct my paper.

\section{References}

[1] Fang,Y.Z. (2012) Study on Braking Energy Recovery System of Pure Electric Car. Hefei Polytechnic University, Hefei.

[2] Panagiotidis, M., Delagrammatikas, G. and Assanis, D. (2000) Development and Use of a Regenerative Braking Model for a Parallel Hybrid E lectric Vehicle. SAE Paper, 2000-01-0995.

[3] Gao, Y.M. and Ehsani, M. (2001) Electronic Braking System of EV And HEV-Integration of Regenerative Braking, Automatic Braking Force Control and ABS. SAE Paper, 2001-01-2478 .

[4] Gao, H.W., Gao, Y.M. and Ehsani, M. (2001) A Neural Network Based SRM Drive Control Strategy for Regenerative Braking in EV and HEV. Electric Machines and Drives Conference, Cambridge, 17 Jun 2001-20 Jun 2001, 571-575.

[5] Zhang, P. (2010) Research and Realization of the Braking Energy Recovery System for Electric Vehicle. Harbin Institute of Technology, Harbin.

[6] Ye, Y.Z. (2013) Study on the Braking Energy Recovery System of Electric Vehicle. Qingdao Technological University, Qingdao.

[7] Chao, H.T. (2012) Research on Regenerative Braking Control Strategy of Wheel Motor Drive Electric Vehicle. Beijing Jiaotong University, Beijing.

[8] Huang, L. (2016) The Coordinated Control of ABS and Regenerative Braking for Electric Vehicle with Four Wheel Independent Drive Wheel Motor. Liaoning University of Technology, Jinzhou.

[9] Zhao, G.Z. (2012) Study on Some Key Problems of Regenerative Braking of Electric Vehicle. Nanjing University of Aeronautics and Astronautics, Nanjing.

[10] Liu, B. (2004) Research and Implementation of the Braking Energy Recovery System Based on Pure Electric Vehicle. Tsinghua University, Beijing.

[11] Li, D.W. (2012) Research on the Control Strategy of the Wheel Drive and Braking Back Energy of Electric Vehicle. Chongqing University of Technology, Chongqing.

[12] Liu, Y.L. (2014) Study on the Compound Recovery Device of Automobile Braking Energy by Wheel Motor Drive. Jilin University, Changchun.

[13] Zhang (2014) Pure Electric Vehicle Energy Efficiency Optimization Method of. Tsinghua University, Beijing.

[14] Liu, X.W. (2015) Study on Regenerative Braking of Distribution Driven Electric Vehicle. Chongqing University, Chongqing.

[15] Li, Z.H. (2014) Mechanism and Experimental Study on the Recovery Mechanism and Experimental Study of Electric Vehicle Driving and Braking. Wuhan University of Technology, Wuhan. 


\section{Submit or recommend next manuscript to SCIRP and we will provide best service for you:}

Accepting pre-submission inquiries through Email, Facebook, LinkedIn, Twitter, etc.

A wide selection of journals (inclusive of 9 subjects, more than 200 journals)

Providing 24-hour high-quality service

User-friendly online submission system

Fair and swift peer-review system

Efficient typesetting and proofreading procedure

Display of the result of downloads and visits, as well as the number of cited articles

Maximum dissemination of your research work

Submit your manuscript at: http://papersubmission.scirp.org/ 